University of Nebraska - Lincoln

DigitalCommons@University of Nebraska - Lincoln

To Improve the Academy

Professional and Organizational Development Network in Higher Education

1994

The Game of Academic Ethics: The Partnering of a Board Game

Stephen E. Sugar

Carol A. Willett

Follow this and additional works at: https://digitalcommons.unl.edu/podimproveacad

Part of the Higher Education Administration Commons

Sugar, Stephen E. and Willett, Carol A., "The Game of Academic Ethics: The Partnering of a Board Game" (1994). To Improve the Academy. 326.

https://digitalcommons.unl.edu/podimproveacad/326

This Article is brought to you for free and open access by the Professional and Organizational Development Network in Higher Education at DigitalCommons@University of Nebraska - Lincoln. It has been accepted for inclusion in To Improve the Academy by an authorized administrator of DigitalCommons@University of Nebraska - Lincoln. 


\section{The Game of Academic Ethics: The Partnering of a Board Game}

\section{Stephen E. Sugar}

University of Maryland, University College

\section{Carol A. Willett}

University of Virginia

A developer of classroom games agrees to a challenging assignment: to develop a classroom board game on the topic of academic ethics. This paper describes how, in partnership with a content expert, he successfully developed and piloted the game for adjunct faculty at the University of Maryland, University College. The two developers, cited as game writer and content expert, work through a variety of design, substance and logistical obstacles to ultimately pilot the game, A Question of Academic Ethics.

It makes me just a wee bit sad That many lectures go unheard 'Cause teachers lock their message to The power of the spoken word.

It makes me just a wee bit mad To see employed for it's own sake

A game or toy or exercise As stuff to keep a class awake. 
So now I ponder, plod and plan

To build those special games that earn

That highest of all accolades:

They join the best of play and learn.

Stephen Sugar

\begin{abstract}
A chance meeting with the Assistant Dean of Faculty Development at the University of Maryland, University College, began it all. An adjunct faculty member with an extensive background in classroom games agreed to develop and deliver a board game on academic ethics to a faculty development workshop 16 weeks hence. He did so knowing that consultants at the Department of Justice had labored for over a year to produce a game on ethical standards, with no conclusion in sight.
\end{abstract}

\title{
The Game Writer's Dilemma
}

Any successful educational game requires two elements - a coherent, engaging game system with clear rules of play, a lively format, and provocative, well-written questions or case studies that encapsulate the topic. In this case, there were other, complicating conditions. First, ethics is itself a complicated, divisive, and highly politicized topic in today's academic environment. Hardly the stuff of which board games are easily made. Second, the audience (composed of adjunct faculty spanning any number of disciplines) was skeptical, sophisticated, and intolerant of sloppy design. Participants, attending an evening workshop on their own time, expected a strong presentation wrapped in an intriguing board game.

\section{Partnering}

Luckily, the game writer unearthed a possible resource-a University of Virginia faculty member who was developing an off-campus course on leadership decision making and ethics. Over lunch, exchanging monographs and resumes with the relish of folks at their twentieth high school reunion, a deal was struck. The game writer 
would develop the game system consisting of game board, rules of play, and game accessories. The instructor, in the role of content expert, was to develop question materials in the form of case studies based on ethical problems in and out of the classroom. This was a multidisciplinary leap of faith as the instructor knew little about the principles of game design, and the game writer had never formally studied ethics.

\section{The Content Expert's Dilemma}

To the uninitiated, a game seems like a simple thing: certainly no great challenge compared to preparing a fifteen-week extension course on ethics. This is only so for those who have never tried to write game questions or case studies for a game format. In the argot of game writers, someone who is well versed in a subject becomes a content expert. The expectation is that they, like a spigot, can easily be turned on and off, producing on demand a stream of concise, unambiguous questions to which there is always a "best", "next best" and "worst" answer to match a sliding point scale based on the relative merits of each answer. This is relatively easy in discussions about geography; it is tortuous in discussions about ethical alternatives. In ethics there are few absolute "right" or "wrong" answers, but an infinitude of "it depends". Moreover, little has been published on academic ethics per se. The challenge became one of finding a way to cast typical classroom problems and decisions in ethical terms. In the end, each situation was tested against the same set of ethical factors to determine the "best", "next best" and relatively "worst" answers. These factors included:

- Consideration for equity and fairness

- Concern for the example being set

- Concern for consistency betweens the end sought and the means used

- Whether position and power were exploited for private gain

- Whether conflicting or differing opinions were sought and considered

- Extent to which implications and trade-offs were fully considered 
- Whether the decision led to the greatest good (or the least pain) for the greatest number.

\section{The Game Plan}

The topic was complicated, the workshop was limited to three hours, and the goal was to facilitate a discussion while keeping a spirit of play. This posed several challenges. The game had to be sufficiently attractive to encourage participation, simple enough for participants to quickly understand the rules and track their progress, and flexible enough to allow credit based on interpretation and evaluation of the case studies. It had to focus on one case study at a time but allow for a balance of instructor control and interactive discussion among players. The game writer found a solution in a race track format in which teams compete to reach the finish, moving forward three spaces for a "best" answer, one space for the "next best," and standing still for selecting the "worst" of three alternatives. Participants were clustered into groups of three or five players to promote interaction and to prevent tie votes. In each round of play, teams read the case, voted on a collective answer, and were awarded spaces by the game writer. The content expert then facilitated a discussion of the ethical principles involved. She led the participants in exploring the implications and trade-offs involved and encouraged faculty members to share how they dealt with these issues in their classrooms each day.

\section{Academic Ethics in the 1990's}

On campuses across America traditional interactions among faculty and students, parents, alumni, administrators, and other faculty are being reexamined in the light of heightened sensitivity to diversity, political correctness, warring pedagogical theories, and enormous pressures on urban campuses to meet the varied expectations of adult learners. Clearly, there is a need to develop ways and means to discuss ethical standards that do not further strain the environment but elicit and balance differing opinions on what constitutes fair and equitable practices. Drawing on the classics of ethical philosophy, the lessons learned from seventeen years of undergraduate and postgraduate teaching, and media coverage of a variety of academic scandals, the 
content expert generated 40 abbreviated case studies. From these, 20 were selected for the game. These cases prompted participants to question whether the instructor in each case behaved in ways that were equitable, whether they set an appropriate example, and whether their actions were consistent with the goals of learning and the values of the institution in which learning was supposed to take place. Teams debated how well the individual in the various cases balanced the implications and trade-offs of their decisions, whether they sought appropriate advice and counsel, and whether they considered differing opinions. Last but not least, participants debated the components of ethical behavior in an academic setting and the utility of periodically asking oneself, "Is this an ethical thing to do?" These discussions brought forth a wealth of practical examples from the participants illustrating the difficulty of determining what is "right" when there are so many differing interpretations of what is "wrong".

\section{The Game Itself}

After a brief introduction to the principles of ethical decision making, the group was prepared for game play: participants were divided into teams; the rules of play were discussed; score sheets were distributed; and the first case study was shown on the overhead projector. Each team was given three minutes to review and then vote on the best answer.

In one case study Professor Smith announces on the first night of class that the syllabus notwithstanding, he requires all students to purchase the latest edition of his seminal work, The Wizard of $O z$ : $A$ Mathematical Discourse, for $\$ 85$.

Is mandating the purchase of one's own book outside of the university review process:

Ethical

Unethical

Open to Question?

[Answer to "Professor Smith" - Unethical, advance 3; Open to Question, advance 1; Ethical, stay put]

( ${ }^{\star}$ See Appendix A for other sample case studies.) 
The score sheets were collected and tallied by the game writer while the content expert brought the workshop back to order. The "best" answer was announced, and the free-for-all began. Participants vied to air what they liked and disliked about each answer, why their team chose as they did, and how their collective experience(s) either validated or disproved the "best" answer. Approached in this way, every question prompted an exploration of multiple, alternative solutions when confronted with similar ethical dilemmas. For every participant there was a different interpretation of the case study, which led to a rich, sometimes chaotic discussion. While one person focused on the "legality" of Professor Smith acting outside the prescribed limits of university review process, another debated the ethics of academic remuneration and the publish-or-perish imperative. The debate proceeded to touch on copyright issues, the distinctions between research and plagiarism, the differing expectations of the university and students regarding the contractual nature of a syllabus, and what constitutes intellectual property.

By the end of the game participants agreed it was important to develop an ethical framework for decision making in the academic sphere. Quite apart from one's own emotional experience and sense of values, faculty members felt they needed to develop a coherent set of ethical factors they consider in deciding upon the best course of action.

Imbued with the strong desire to win in the game of academic ethics, players challenged not only interpretation of the case material itself, but the method of scoring, the reliability of research data and sources, and the basis for selecting the teams. Everything about the evening was recast as an "ethical question." It was a bit like giving a small boy a hammer: all the world becomes a nail. The volume, vigor, and warmth generated by this discussion resulted in a thoroughly productive debate on the role and effect of academic ethics. Participants commented that the game had focused their attention on the ethical implications of their behavior in and out of the classroom and had helped to generate a series of questions they could use in reaching decisions. The game was unanimously deemed a success. 


\section{Lessons Learned}

In retrospect, after the workshop concluded and participants critiques had been reviewed, both the game writer and content expert agreed that there were several things they would do differently. First, they would have piloted the game with a test group to assess the relevance of the "best," "next best," and "worst" answers. Disagreement among workshop participants regarding the selection of a "best" answer served to fuel a lively debate about the criteria involved. However, without skilled facilitation, the game could have degenerated into a shouting match. Secondly, pre-testing the game could have helped clear up possible misinterpretations of the case studies and more tightly focused attention on the ethical dilemma involved. Third, both the game writer and content expert agreed that they would greatly reduce the number of cases to allow enough time to fully discuss the implications of each.

\section{Post Script}

The Game of Academic Ethics was a success. The workshop evaluations showed that $87 \%$ of the participants agreed or strongly agreed that "after taking this workshop, I feel better prepared/more knowledgeable about academic ethics." In addition, comments stated that the most helpful parts of the workshop were "pretty much the whole workshop and discussions, principles of making ethical decisions, and the case-study discussions." (See Appendix E for rest of workshop evaluation.)

The participants enjoyed and learned from the case studies. The game has been used by at least one other faculty member at the University of Maryland, University College, and the game has been shown to three other audiences, including an international conference, with very positive results. In addition, a major publisher has indicated it wishes to include the game format in its fall catalog. Best of all, it was designed in a mere 16 weeks. At last report, the Department of Justice was still working on its ethical standards game. 


\section{APPENDIX A}

\section{Academic Ethics Gameboard}
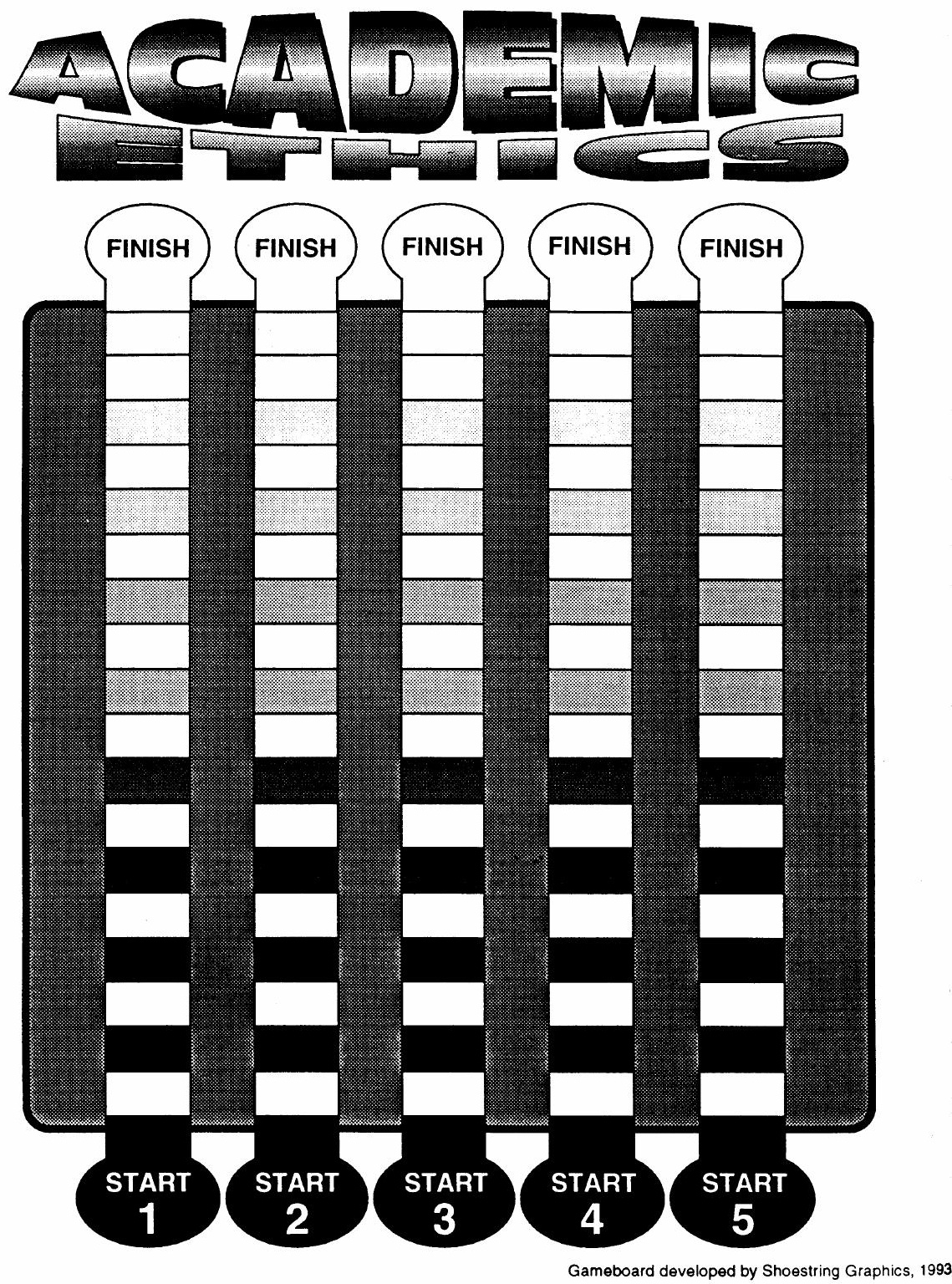


\section{APPENDIX B \\ Rules of Play - A Question of Ethics}

Object of Game

Learning Objective

Materials

Time of Play

Preliminaries
To be the first team to advance across the finish line.

To create a dialogue about academic ethics both in and out of the classroom.

1 game board transparency; 10 sets of score sheets; 1 set of 4 - 10 questions; 1 overhead projector

\section{5 minutes to 3 hours}

Your class will be divided into teams of three or five members each.

Your team will select a number that matches a lane on the gameboard - number 1, 2, 3, 4, or 5 .

Your team will receive a set of score sheets.

\section{Game Play: Round 1}

$>$ The instructor presents a short case study on the overhead. The case can be answered either Ethical, Unethical, or Open to Question.

$>$ Each team will be given 3 minutes to determine their selection.

$>$ Each team records their selection on the score sheet.

$>$ The instructor collects score sheets.

$>$ The instructor gives the preferred alternative, and then the second and third choices.

$>$ Each team advances the number of game board spaces in accordance with the appropriateness of their answer, as follows:

most appropriate answer. advance 3 spaces

second most appropriate answer. advance 1 space

least appropriate answer. stay put

\section{Round 2 to End of Game}

Each round is played the same way until the end of the game.

\section{End of Game}

$>$ The first team to cross the finish line is declared the winner.

$>$ If no one has crossed the finish line, the team closest to the finish line is declared the winner. 


\section{APPENDIX C Sample Case Studies}

1. Dr. Hiwakawa announces to her postgraduate class that original theme papers (research topics to be assigned by the instructor) will account for $70 \%$ of the final grade. Moreover, she informs the class that the best of these themes will be incorporated in a compilation of substantive readings she is under contract to produce for the University Press.

If professors include student-produced research as part of the body of their own, is this:
a. Ethical?
b. Unethical?
c. Open to Question?

3. Paul Ankara, an adjunct professor, announces early in the semester that as a matter of policy, he grades on a curve and assigns no more than $10 \% \mathrm{~A}$ 's in any given class. Mr. Ankara also announces that he is open to negotiation on how these A's may be earned.

Is this practice apt to be construed as:
a. Ethical?
b. Unethical?
c. Open to Question?

3. Last month's copy of the New Yorker had an absolutely perfect cartoon illustrating the central thesis of one of your lectures. In light of copyright law, how would you characterize making a view graph of the cartoon to project one time in class?
a. Ethical?
b. Unethical?
c. Open to Question?

\section{Key}

\#1 - Open to Question, advance 3; Ethical, advance 1; Unethical, stay put

\#2 - Open to Question, advance 3; Ethical, advance 1; Unethical, stay put

\#3 - Ethical, advance 3; Open to Question, advance 1; Unethical, stay put 


\section{APPENDIX D Ethics Reference Materials}

Bok, S. (1989). Lying: Moral choice in public and private life. New York: Vintage Books.

Hampshire, S. (Ed.) (1978). Public and private morality. Cambridge: Cambridge University Press.

Haughey, J. C. (Ed.) (1979). Personal values in public policy: Conversations on government decisionmaking. New York: Paulist Press.

Runkle, G. (1982). Ethics: An Examination of contemporary moral problems. New York: Holt Rinehart \& Winston. 


\title{
APPENDIX E Workshop Evaluations
}

Total number of attendees: 16

Total number of respondents: 10

\author{
UNIVERSITY OF MARYLAND UNIVERSITY COLLEGE \\ THE GAME OF ACADEMIC ETHICS \\ Thursday, August 5, 1993 \\ presenters: steve sugar and carol willett
}

1. The workshop objectives were clear.

strongly agree agree undecided disagree strongly disagree
$60 \%(6 / 10)$

2. The presenters were well-organized, articulate, and supportive.

Steve sugar:

strongly agree agree undecided disagree strongly disagree
$80 \%(8 / 10)$

Carol willett:

strongly agree
$80 \%(8 / 10)$
$20 \%(2 / 10)$ undecided disagree strongly disagree

3. After taking this workshop, I feel better prepared/more knowledgeable about academic ethics.

strongly agree agree undecided disagree strongly disagree $50 \%(5 / 10) \quad 20 \%(2 / 10)$. $10 \%(1 / 10)$

Note, Two attendees did not respond.

4. The parts of the workshop that were the most helpful were:

a. Pretty much the whole workshop and discussions. $\times 2$

b. Discussions/searching for principles during triads.

c. Principles of making ethical decisions. $\times 2$

d. Academic ethics game.

e. The case-study discussions. $\times 4$

f. Group interaction. Steve and Carol were super!! Exposure to new ideas and topics.

5. The parts of the workshop that were least helpful were:

a. Exposure to only 2 games.

b. Scavenger hunt. $\times 2$

c. Initial game

d. The first. exercise.

e. The items that were on the flip chart.

6. Please use the space on the other side of this sheet to add any additional comments about the workshop or to provide suggestions for future Faculty Development programs.

a. Excellent presentation!!

b. Excellent. I look forward to the next one.

c. For me religious principles of conscience and community prevail.

d. I would have liked to see inclusion of time for more extensive discussion of actual cases from our own experiences. A handout on details of coypright rules, etc., as applied to the classroom, would be helpful. 